\title{
Chronic kidney disease is associated with severe coronavirus disease 2019 (COVID-19) infection
}

\author{
Brandon Michael Henry ${ }^{1}$. Giuseppe Lippi ${ }^{2}$
}

Received: 11 March 2020 / Accepted: 22 March 2020 / Published online: 28 March 2020

(c) Springer Nature B.V. 2020

\section{Editor,}

As the novel Coronavirus Disease 2019 (COVID-19) outbreak expands, identification of predictive factors for severe infection is essential to enable risk stratification, optimize reallocation of hospital resource, and guide public health recommendations and interventions. Chronic Kidney disease (CKD) is associated with an increased risk of both inpatient and outpatient pneumonia [1]. Moreover, the pneumoniarelated mortality rate in CKD patients seems to be 14-16 times higher than in the general population [2]. In this article, we aim to explore the potential association between CKD and severity of COVID-19 infection.

A search of electronic databases, based on Medline (PubMed interface), Scopus and Web of Science, was carried out with the keywords "chronic renal disease" OR "chronic kidney disease" OR "clinical characteristics" AND "coronavirus 2019" OR "COVID-19" OR "2019-nCoV" OR "SARS-CoV-2", between 2019 and present time (i.e., March $9,2020)$ with no language restrictions applied. The title, abstract and full text of all articles identified that matched the search criteria were assessed, and those reporting the rate of CKD in COVID-19 patients with clinically validated definition of "severe disease" were included in this metaanalysis. The references of all identified studies were also analyzed (forward and backward citation tracking) to identify other potentially eligible articles.

A meta-analysis was performed on retrievable data, including the estimation of the odds ratio (OR) and its $95 \%$

Brandon Michael Henry

Brandon.henry@cchmc.org

1 Cardiac Intensive Care Unit, The Heart Institute, Cincinnati Children's Hospital Medical Center, 3333 Burnet Avenue, Cincinnati, OH 45229, USA

2 Section of Clinical Biochemistry, Department of Neuroscience, Biomedicine and Movement, University of Verona, Verona, Italy confidence interval (95\% CI) in patients with or without severe forms of COVID-19. The statistical analysis was performed with MetaXL, software Version 5.3 (EpiGear International Pty Ltd., Sunrise Beach, Australia). The study was carried out in accordance with the Declaration of Helsinki and with the term of local legislation.

Overall, 84 articles could be originally detected based on our electronic and reference search which, after screening by title, abstract and full text, 80 were excluded as not specifically related to COVID-19 $(n=25)$, were review articles $(n=7)$, did not provide relevant data $(n=28)$, were editorials $(n=10)$, did not include information on severity and/or comorbidities $(n=8)$, compared patients by mortality but not by severity $(n=1)$, or compared mild to critical cases $(n=1)$. Therefore, a final number of four studies could be included in our meta-analysis, including 1389 COVID-19 patients, among which 273 (19.7\%) were classified as having severe disease [3-6].

The essential characteristics of included studies are summarized in Table 1, whilst the individual and pooled ORs for CKD predicting severe COVID-19 is shown in Fig. 1. No study individually found CKD as significant clinical predictor of severe COVID-19. However, when data of individual studies were pooled, a significant association of CKD with severe COVID-19 was observed, with no relevant heterogeneity [OR 3.03 (95\% CI 1.09-8.47), $I^{2}=0.0 \%$, Cochran's $Q, p=0.84]$.

Based on a contrite meta-analysis of early and preliminarily available data, CKD seems to be associated with enhanced risk of severe COVID-19 infection. Patients with CKD should hence be advised to take extra precaution to minimize risk exposure to the virus. Physicians should also be engaged in close monitoring of CKD patients with suspected COVID-19, for timely detecting signs of disease progression. Finally, the presence of CKD shall be regarded as an important factor in future risk stratification models for COVID-19. 
Table 1 Characteristics of included studies

\begin{tabular}{|c|c|c|c|c|c|c|c|c|c|}
\hline \multirow[t]{2}{*}{ Study } & \multirow[t]{2}{*}{ Setting } & \multirow[t]{2}{*}{ Sample size } & \multirow[t]{2}{*}{ Outcomes } & \multicolumn{3}{|c|}{ Severe patients } & \multicolumn{3}{|c|}{ Non-severe patients } \\
\hline & & & & $n(\%)$ & Age $(\text { years })^{\mathrm{a}}$ & Women $(\%)$ & $n(\%)$ & Age (years) ${ }^{\mathrm{a}}$ & Women $(\%)$ \\
\hline $\begin{array}{l}\text { Guan W et al. } \\
2020\end{array}$ & China & 1099 & $\begin{array}{l}\text { Admission to } \\
\text { ICU, MV, } \\
\text { death }\end{array}$ & $173(15.7 \%)$ & $52(40-65)$ & 42 & $926(84.3 \%)$ & $45(34-57)$ & 42 \\
\hline Liu Y et al. 2020 & China & 12 & $\begin{array}{l}\text { Respiratory } \\
\text { failure, MV }\end{array}$ & $6(50 \%)$ & $64(63-65)$ & 50 & $6(50.0 \%)$ & $44(35-55)$ & 17 \\
\hline $\begin{array}{l}\text { Wang D et al. } \\
2020\end{array}$ & China & 138 & $\begin{array}{l}\text { Clinical } \\
\text { variables, MV, } \\
\text { death }\end{array}$ & $36(26.1 \%)$ & $66(57-78)$ & 39 & $102(73.9 \%)$ & $51(37-62)$ & 48 \\
\hline $\begin{array}{l}\text { Zhang JJ et al. } \\
2020\end{array}$ & China & 140 & $\begin{array}{l}\text { Respiratory } \\
\text { distress/insuf- } \\
\text { ficiency }\end{array}$ & $58(41.4 \%)$ & $64(25-87)$ & 43 & $82(58.6 \%)$ & $52(26-78)$ & 54 \\
\hline
\end{tabular}

$M V$ mechanical ventilation, $I C U$ intensive care unit

${ }^{\mathrm{a}}$ Age data presented as median (IQR)

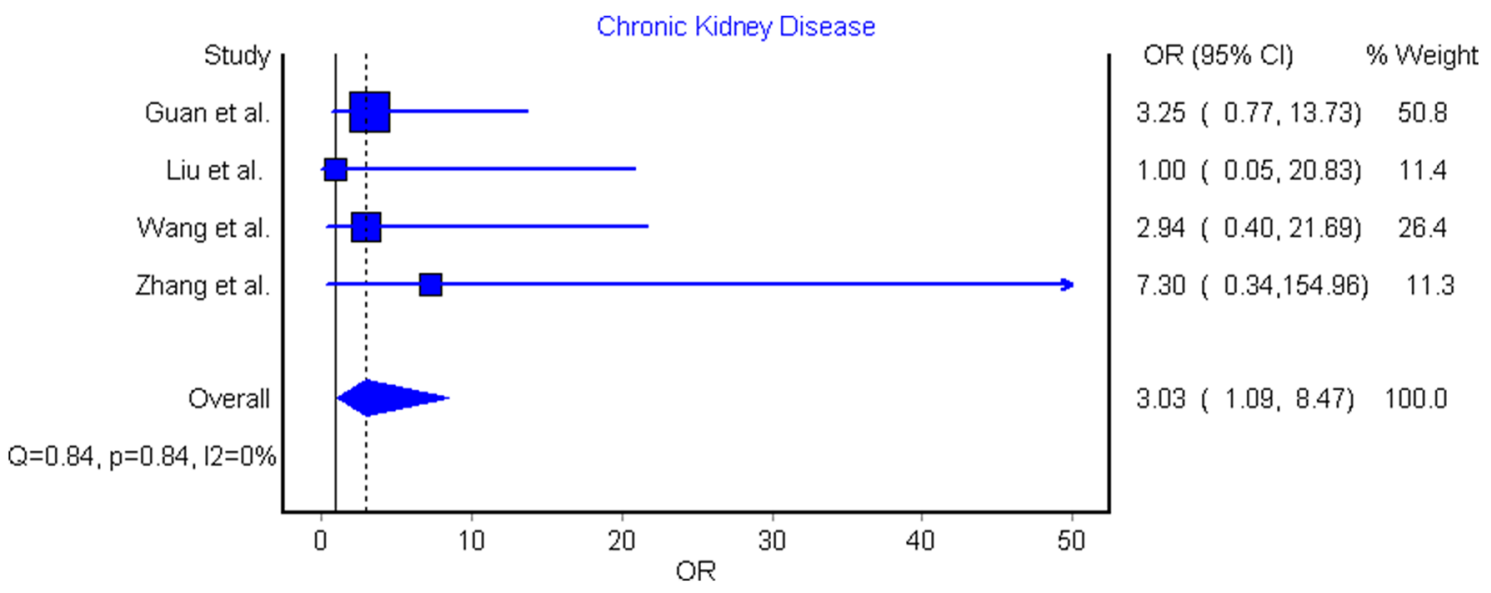

Fig. 1 Forest plot of demonstrating association of chronic kidney disease with severe COVID-19 disease

Funding None.

\section{Compliance with ethical standards}

Conflict of interest None declared.

\section{References}

1. Chou C-Y, Wang S-M, Liang C-C et al (2014) Risk of pneumonia among patients with chronic kidney disease in outpatient and inpatient settings. Medicine (Baltimore). https://doi.org/10.1097/ MD.0000000000000174

2. Sarnak MJ, Jaber BL (2001) Pulmonary infectious mortality among patients with end-stage renal disease. Chest 120:18831887. https://doi.org/10.1378/chest.120.6.1883
3. Guan W-J, Ni Z-Y, Hu Y et al (2020) Clinical characteristics of coronavirus disease 2019 in China. N Engl J Med. https://doi. org/10.1056/NEJMoa2002032

4. Liu Y, Yang Y, Zhang C et al (2020) Clinical and biochemical indexes from 2019-nCoV infected patients linked to viral loads and lung injury. Sci China Life Sci 63:364-374. https://doi. org/10.1007/s11427-020-1643-8

5. Wang D, Hu B, Hu C et al (2020) Clinical characteristics of 138 hospitalized patients with 2019 novel coronavirus-infected pneumonia in Wuhan, China. JAMA. https://doi.org/10.1001/ jama.2020.1585

6. Zhang J-J, Dong X, Cao Y-Y et al (2020) Clinical characteristics of 140 patients infected with SARS-CoV-2 in Wuhan, China. Allergy. https://doi.org/10.1111/all.14238

Publisher's Note Springer Nature remains neutral with regard to jurisdictional claims in published maps and institutional affiliations. 